\title{
Health literacy in rural Jamaica: visual aides to assist and increase medication adherence
}

\begin{abstract}
Similar to many Americans, the people of Jamaica are facing many health issues. Specifically, there are concerns with an ever aging population which continues to grow in size at an astounding rate of 11.3 percent each year. ${ }^{1}$ Who will take care of this aging population, what services will be available, and how the elderly will maintain a reasonable quality of life are all questions that are facing Jamaica in the near future People are living longer and with this increase in life-years come other concerns such as the cost of care, who will administer the care, and access to care as travel becomes more difficult with increased age. With an acknowledgement of these concerns also comes the realization that many in the rural Jamaican population are illiterate on some level.

Health literacy is defined as the extent to which people have the capacity to obtain basic health information; this information is used to make informed decisions about their health. Health literacy is paramount if patients are going to benefit from health care. People who cannot read or understand the high level of grammar associated with healthcare instruments, diagnostic tests, directions and medications for care may experience confusion in negotiating the health care system, and are significantly handicapped in the task of selfcare or caring for family members. Individuals with inadequate health literacy compared to those with adequate health literacy knew much less about their chronic diseases. ${ }^{2}$

Many solutions have been offered to address the concerns of literacy when it comes to Jamaica's middle and older aged population. ${ }^{2}$ One solution that has been proposed by groups of researchers is that physicians spend more time giving advice to patient ensuring that they are aware of the directions for the medications they are taking. Another solution is the development of culturally sensitive, low-literacy educational materials to improve patient awareness of prostate cancer and the frequency and importance of diagnosis at earlier stages and other chronic diseases. ${ }^{2}$
\end{abstract}

Volume 2 Issue 5 - 2015

\author{
Darry Coverson \\ $\mathrm{MPH}$, Mercer University, USA
}

Correspondence: Darry Coverson, MPH, Mercer University, USA,Tel (404)8380230,Email coverson_d@med.mercer.edu

Received: March 19, 2014 | Published: August 31, 2015

\section{Introduction}

Similar to the United States, Jamaica has many health concerns that are facing its people. Specifically, there are concerns with an ever aging population which continues to grow in size at an astounding rate. Who will take care of this aging population, what services will be available, and how the elderly will maintain a reasonable quality of life are all questions that are facing Jamaica in the future. However, these concerns and questions are also being asked of many other countries as the global population continues to increase in age. Elderly is defined as being over the age of 60 by the World Health Organization. ${ }^{1}$ People are living longer and with this increase in life-years come other concerns such as the cost of care, who will administer the care, and access to care as travel becomes more difficult with increased age. The Jamaican Ministry of Health data shows that the prevalence of chronic diseases is greatest for those in excess of 65years old with the prevalence of health illiteracy also increasing in this age group when compared to the overall population. ${ }^{3}$

Health literacy has three levels: functional health literacy that includes the basic reading and writing needed to be able to function in daily life, communicative or interactive health literacy that includes more advanced cognitive and literacy skills which combine with social skills to enable someone to participate in a range of activities and apply information to changing situations; and critical health literacy that comprises of more advanced cognitive and social skills that a person can use to exert more control over their lives. ${ }^{4}$
Chronic diseases are at the bedrock of global concern not only for the elderly but also for the middle aged as well. Unlike the infectious diseases of the past these chronic diseases last until death, many of which lead to death. Hypertension, diabetes, arthritis, kidney/ bladder issues, and other cancers are just a short list of chronic diseases that Jamaicans face. Current studies done by the North American Journal of Medical Sciences revealed that the prevalence of chronic diseases increased from 8 per 1,000 in 2002 to 56 per 1,000 in $2007 .{ }^{5}$ Chronic diseases like diabetes mellitus have a prevalence of $17.9 \%$ in the adult population. ${ }^{6}$ To further compound this problem many older and middle-aged Jamaicans have little to no formal education. This is especially true in rural areas where education and healthcare is scarce. Education develops particular skills and the knowledge base of individuals, which is the catalyst for inquiry, reasoning and lifestyle changes. It is the empowerment that shapes the health and wellbeing of the educated populace. ${ }^{7}$

Even those who are formally educated can be "health illiterate". This is indicated in approximately $34 \%$ of all elderly Jamaicans taking and following their prescription drug medication directions. ${ }^{2}$ Recent census data shows that the proportion of Jamaicans 60 years of age and older is expected to grow from $10.49 \%$ in 2005 to over $14 \%$ by $2025^{8}$ In addition to this, of the $34 \%$ who actually took their medications $43 \%$ self-reported having been diagnosed with cancer, and $3.8 \%$ with bladder/kidney problems. ${ }^{2}$ Literacy does not equate to health literacy. To ensure that this population is adequately competent with 
understanding and managing health concerns there must be culturally competent health education materials which are easy to understand for this segment of the Jamaican population. These materials must easily translate the instructions and directions so the person is aware of what they should be doing on a daily basis to mitigate their current health concern or issue.

Health literacy is defined as the extent to which people have the capacity to obtain basic health information; this information is used to make informed decisions about their health. Health literacy is paramount if patients are going to benefit from health care. People who cannot read or understand the high level of grammar associated with healthcare instruments, diagnostic tests, directions and medications for care may experience confusion in negotiating the health care system, and are significantly handicapped in the task of self-care or caring for family members. A significant statistical relationship was found between functional health literacy and the quantitative components of general functioning literacy. ${ }^{2}$

Again, literacy should not be an obstacle or a stumbling block when it comes to medication adherence, health literacy, health seeking behavior and overall health. This issue is vital to the continued growth of Jamaica and its people because it speaks to the disenfranchisement that ensues when one is uneducated especially when it concerns health. Health status should not be contingent upon education or illiteracy. However, since it is we must ensure that those who are left behind don't stay there.

Many solutions have been offered to address the concerns of literacy when it comes to Jamaica's middle and older aged population one solution that has been proposed by groups of researchers is that physicians spend more time giving advice to patients ensuring that they are aware of the directions for the medications they are taking. Another solution is the development of culturally sensitive, low-literacy educational materials to improve patient awareness of prostate cancer and the frequency and importance of diagnosis at earlier stages. ${ }^{2}$ Gender and age specific research should reduce gender disparities among older persons in Jamaica; taking programs to "where men are" or "where women are" for example in an effort to improve health literacy and prevention efforts should be the focus. ${ }^{9}$

Moreover, culturally sensitive, low-literacy educational materials to improve patient awareness of chronic diseases also increases selfefficacy, health improving, and health seeking behaviors. Patients with limited literacy and who also have chronic diseases benefit from health education and disease management. A two pronged attack of the health literacy and disease management problem assists in the selfefficacy of the patient thereby increasing their knowledge, awareness, and ability to maintain their medication regimen. In the case of the aforementioned pilot study low health literacy was found to be highly prevalent among Medicare enrollees who experienced a large burden of disease of chronic illness. Forty-two percent of Medicare recipients read at less than a sixth grade level. This is also similar to many rural elderly Jamaicans who attend primary school but aren't able to afford higher level education. The similarity in the data as well as the correlation between education and medication adherence was one of the primary reason this pilot study became a foundation for this literacy capstone project.

Further solutions to the problem of health illiteracy are associated with health literacy best practices. Best practices for health communication and health literacy are very similar in that they both point to ease of reading or readability as well as cultural competence as a key foundation for the information to be disseminated. Best practices for health literacy are to identify users of the health information and services that will be used. ${ }^{10,11}$

Evaluating users' understanding before, during, and after the introduction of information and services, this is also relevant for instructions given about prescription usage, dosage and adherence. ${ }^{11}$

Cultural competence is paramount in educating a population on health issues. Cultural factors include race, ethnicity, language, nationality, religion, age, gender, sexual orientation, income level, and occupation. ${ }^{11}$ A further acknowledgement of the cultural perspective of best practices revolves around the need for those who are illiterate to not feel as though they are being singled out or "picked on" by those who are literate or health literate. This can be curtailed by having healthcare providers understand the importance of being health literate in the sense that they should be proficient in providing patient education in terms of health seeking behaviors. ${ }^{12}$

The purpose of this project is to address health literacy among the elderly Jamaican population and their medication adherence; health literacy plays a paramount role in whether or not people adhere to their prescriptions, medications, and continues with their health seeking behaviors. This project is vitally important because it focuses on increasing health literacy in the rural illiterate and health illiterate population. The project has a foundation within the health belief model as well (HBM). Self-efficacy will be increased when individuals believe that they are better able to take care of themselves due to having a visual prescription aid. In the case of those who are unable to read or write this is all the more important as they are the most vulnerable in the population. As a volunteer with American Jamaican Link health education materials will be created and prescription visual aides (picture prescriptions) that are easily understood by those who have trouble with traditional medical terminology and this will occur within the rural setting of Black River, Balaclava and Parottee, St Elizabeth Parish, Jamaica.

\section{Methods procedures}

The problem will be addressed by creating prescription drug visual aides that will assist the elderly health illiterate population with their medication adherence and to promote health literacy. The following goals have been created for this project: to provide the elderly and health illiterate population with visual prescription aides that will mitigate prescription noncompliance and to increase medication self-efficacy. The objectives for this project are to create visual prescriptions for twenty-five elderly health illiterate Jamaican residents, have the visual prescription placed in the patient's medical records at the local or regional medical facility.

This project will be based within the community and the local or regional healthcare facility. The procedures for this project consisted of a series of informal conversations with the local elderly population. Participants will be asked how many medications they take, how often they take them and if they intentionally do not take them. For the sake of this project I have defined "elderly" as ages sixty and above. Old is defined as sixty and above and can be subcategorized into the following: young old, middle old, and old-old. ${ }^{1}$ They will also be asked questions about participant medications, their effectiveness, how often they take them, when they take them, and if they have difficulty knowing when to take them. I will also administer a health 
literacy questionnaire to understand what grammar level prescription directions should be written at. The setting for the collecting of data was under the controlled supervision of the clinic supervisor, preceptor, and academic advisor. The participants in the sampling frame will be patients of Dr. Clyde Green on his numerous visits to St. Elizabeth, Jamaica. The sample frame will consist of current patients and will afford the study with more realistic results. These patients will have had the same physician but the only medication to their care will be the template which they will use to assist in taking their medications. The demographic population for this project will be the elderly and health illiterate. The materials used for this project will be paper and pencil recording of the types of prescriptions each individual is taking, what they should be taking and if they feel comfortable taking their prescriptions currently. A list of the medications that will be taken to Jamaica by Dr. Clyde Green has been received and has been narrowed down to only include prescription that aid in mitigating chronic diseases and these medications are being used as the medication template.

The instrumentation used for this project will be twofold: verbal questioning and a written questionnaire. Since this is a population of both literate and illiterate people, questions will be asked verbally and a questionnaire will be administered. However, I will still administer a questionnaire for the purpose of showing what the true literacy level of the population is. Based upon the responses given during the questionnaire a literacy level will be derived. The data collected will be saved and documented using a personal PC.

\section{Results}

A sample size of twenty-five was used for administering the health literacy questionnaire in the following locations: Black River, Balaclava, and Parottee respectively. A questionnaire was given to illustrate how prescription medication instructions should be written currently and in the future (Table 1). Respondents were also asked if they thought having something to look at or indicate when to take their medications would help (Table 2). The results of the project indicate that literacy for the elderly population in rural Jamaica is a national health concern. If individuals are unable to understand what type of medications they are taking and why, they are less likely to take them regularly and as scheduled. Yet, many of these same elderly understand and acknowledge that they also need some sort of assistance in terms of taking and understanding their medications.

Table I Health literacy test results (25 Respondents)

\begin{tabular}{lll}
\hline Education literacy level & Total & Percentage \\
\hline Third Grade or Below (0-13 score) & 16 & 64 \\
Fourth to Sixth Grade (19-44 score) & 4 & 16 \\
Seventh to Eighth Grade (45-60 score) & $\mathrm{I}$ & 4 \\
High School Level (6I-66 score) & $\mathrm{I}$ & 4 \\
Ability to read and not write* & 3 & 12 \\
Total & 25 & 100 \\
\hline
\end{tabular}

\section{Health literacy test results (25 Respondents)}

*These three individuals were from Black River, St. Elizabeth Parish, and Jamaica. No other locations had respondents who could read and not write indicating some form of formal education.
Table 2 Respondents who believed visual aides would make medications easier to take

\begin{tabular}{llll}
\hline $\begin{array}{l}\text { Education literacy } \\
\text { level }\end{array}$ & $\begin{array}{l}\text { \# of people who } \\
\text { wanted and aid }\end{array}$ & Total & Percentage \\
\hline $\begin{array}{l}\text { Third Grade or Below } \\
(0-13 \text { score) }\end{array}$ & 15 & 16 & 60 \\
$\begin{array}{l}\text { Fourth to Sixth Grade } \\
\text { (19-44score) }\end{array}$ & 2 & 4 & 8 \\
$\begin{array}{l}\text { Seventh to Eighth } \\
\text { Grade (45-60 score) }\end{array}$ & 1 & 1 & 4 \\
$\begin{array}{l}\text { High School Level (6I- } \\
66 \text { score) }\end{array}$ & 0 & 1 & 0 \\
$\begin{array}{l}\text { Ability to read and not } \\
\text { write* }\end{array}$ & 2 & 3 & 8 \\
$\begin{array}{l}\text { Total } \\
\text { Total that believed an } \\
\text { aid would }\end{array}$ & 20 & 25 & 100 \\
help & & $20 / 25$ & 80 \\
\hline
\end{tabular}

\section{Discussion}

\section{Outcomes}

There were several outcomes and results that came to fruition as a result of this capstone project. The following conclusions were made: rural elderly Jamaicans believe visual medication aides will benefit them, results indicated that a health literacy problem does exist for the area, and visual aides are needed due to the literacy level and health literacy level of the region. Furthermore, a recommendation made was that a follow up would be needed in the future to determine adherence based upon the addition of visual aides. The follow up will take place on July 5th-13th and will be administered by the American-Jamaican charitable Foundation. It was found in a study similar to this one that illustrated medication instructions along with educational instruction using the teach-back method, significantly improved medicationrelated self-efficacy as well as adherence among the community dwelling elders. ${ }^{10}$ The teach-back method is for patients with limited health literacy and asked to restate what they have learned back to the instructor. ${ }^{13}$ In this strategy, the educator- physician- tailors teaching and reassesses comprehension until the patient has mastered the information. ${ }^{13}$ It is my hope that these same results are duplicated in Black River, Balaclava, and Parottee Jamaica.

\section{Limitations}

However, there are limitations to the project that will need to be addressed to further ensure that the findings that were made can be accepted in general or universally. The sample size used for this project was relatively small (25) and this small size may play a role in respondents indicating their receptiveness to visual aides. Although those that responded to the questionnaire stated visual aides would help the data derived also shows a trend where those who are less educated feel more of a need for visual aides while those elderly that are more educated felt less of a need. Again, a larger sample size would be needed. However, it does make sense that those who are more educated would be less likely to need a visual aid; but literacy does not equate to health literacy. As an aside, it is also important to 
acknowledge the importance of healthcare providers to also be health literate in the sense that they should be proficient in providing patient education in terms of health seeking behaviors.

\section{Tangible products}

Furthermore, the American Jamaican Link Charitable Foundation was provided a visual prescription aid which was given as a deliverable to the organization. This template allows the organization to edit and tailor as they see fit for their many missions to the Caribbean and Western Africa.

\section{Future implications}

Implications for this project could be far reaching on both the local and national level in Jamaica. If the Jamaican government saw the public health disparity between those in urban versus rural areas they would see that there is a stark difference in health outcomes between the two. As a result if the Jamaican government took the initiative to make health literacy or overall literacy a priority for its people the health of future generations will be preserved. An increase in the education budget on the national level in Jamaica would most certainly combat the harsh realities many rural Jamaicans face.

Furthermore, it must be mentioned here that health literacy and literacy overall does not affect the elderly alone. Socio-economic status will also play a pivotal role Jamaica's future health status. Poverty is undoubtedly correlated with ill-health; in particular health status, and health care-seeking behaviors. ${ }^{14}$ The wealthiest in the society are expected to experience better health due to their knowledge of health risks and their access to the resources necessary to avoid such risks and treat emerging health conditions. ${ }^{15}$ Many youths in the rural and urban areas have little to no formal education as well with primary school being the only government funded levels of education for all its citizens. Ensuring that education was a priority for future generations would secure Jamaica's future nationally and internationally.

\section{Acknowledgements}

None.

\section{Conflict of interest}

The author declares no conflict of interest.

\section{References}

1. World Health Organization. Definition of an older or elderly person. Geneva: Retrieved from World Health Organization; 2014.
2. Paul A, Bourne CM. Health literacy and health seeking behavior among older men in a middle income nation. Patient Related Outcome Measures. 2010:39-49.

3. Bourne PA. An epidemiological transition of health conditions, and health status of the old-old-to-oldest-old in Jamaica: A comparative analysis. North American Journal of Medical Sciences. 2009;1(4):211219.

4. Taggart J. A systematic review of interventions in primary care to improve health literacy for chronic disease behavioral risk factors. $B M C$ Family Practice. 2012;13(49):1-12.

5. McDaniel PA. The changing faces of diabetes, hypertension and arthritis in a Caribbean population. North N Am J Med Sci. 2010;2(5):221-229.

6. The Jamaican Hypertension Prevalence Study. Journal of the National Medical Association. 2011:561-565.

7. McGrowder PA. Rural health in Jamaica: examining and refining the predictive factors of good health status of rural residents. The International Electronic Journal of Rural and Remote Health Research, Education, Practice and Policy. 2009;9(1116):1-13.

8. Clarke EP. Population Trends and Challenges in Jamaica. Journal of Aging in Emerging Economies. 2008:24-32.

9. Eldemire-Sheared CM. Health Status and Health-seeking Behaviour of Jamaican Men Fifty-five years and Over. West Indian Medical Journal. 2011:322-329.

10. Martin D, Kripalani S, Durapau VJ. Improving Medication Management among At-risk Older Adults. J Gerontol Nurs. 2012;38(6):24-37.

11. U.S. Department of Health and Human Services. Quick Guide to Health Literacy. 2014.

12. Scheckel ME. Addressing health literacy: the experiences of undergraduate nursing students. J Clin Nurs. 2010;19(5-6):794-802.

13. Negarandeh R, Mahmoodi H, Noktehdan H, et al. Teach back and pictorial image educational strategies on knowledge about diabetes and medication/dietary adherence among low health literate patients with type 2 diabetes. Prim Care Diabetes. 2013;7(2):111-118.

14. Bourne PA. Health status and Medical Care-Seeking Behavior of the poorest $20 \%$ in Jamaica. International Journal of Collaborative Research on Internal Medicine \& Public Health. 2009;1(6\&7):167185.

15. McGrowder P. Socio-demographic determinants of health status of elderly with self-reported diagnoses chronic medical conditions in Jamaica. Health Medicine and Healthcare Journal. 2010:101-111. 